\title{
Ganoderic acid A exerts antitumor activity against MDA-MB-231 human breast cancer cells by inhibiting the Janus kinase $2 /$ signal transducer and activator of transcription 3 signaling pathway
}

\author{
YUGUANG YANG $^{1}$, HONGFENG ZHOU $^{1}$, WENMING LIU ${ }^{1}$, JIN WU $^{1}$, XIAOLONG YUE $^{1}$, JINCAI WANG $^{1}$,

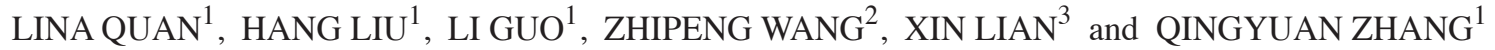 \\ ${ }^{1}$ Department of Medical Oncology, Harbin Medical University Cancer Hospital, Harbin, \\ Heilongjiang 150081; ${ }^{2}$ Department of Medical Oncology, The Fourth Affiliated Hospital of Harbin \\ Medical University; ${ }^{3}$ Department of Medical Oncology, The First Affiliated Hospital of \\ Harbin Medical University, Harbin, Heilongjiang 150001, P.R. China
}

Received December 29, 2016; Accepted August 7, 2018

DOI: $10.3892 / \mathrm{ol} .2018 .9475$

\begin{abstract}
Breast cancer is a common malignant tumor among females, with triple-negative breast cancer being an important type accounting for $15-20 \%$ of all breast cancer cases. Triple-negative breast cancer is one of the most aggressive types of cancer without standard adjuvant chemotherapy. Ganoderic acid A (GA-A) is one of the major bioactive Ganoderma triterpenoids isolated from Ganoderma, which are recognized for their preventative and therapeutic effects. In the present study, the antineoplastic effect of GA-A on human breast cancer was investigated and the pro-apoptotic function of Janus kinase (JAK)2 and signal transducer and activator of transcription (STAT) 3 on the function of GA-A was revealed. GA-A treatment inhibited the invasion of MDA-MB-231 cells. In addition, GA-A exhibited significant antitumor activity by enhancing the apoptotic index and reactive oxygen species production. In the present study, GA-A was identified to directly inhibit JAK2 phosphorylation and STAT3 downstream activation. In addition, GA-A suppressed STAT3 target gene expression, including B cell lymphoma-extra-large and Myeloid cell leukemia 1, resulting in elevated levels of proteins associated with mitochondrial apoptosis in addition to inhibitors of cyclin-dependent kinase. GA-A, in combination with AG490, a JAK2/STAT3 inhibitor, further decreased MDA-MB-231 cell viability. In conclusion, GA-A treatment inhibited breast cancer cell viability via JAK2/STAT3 downregulation and
\end{abstract}

Correspondence to: Professor Qingyuan Zhang, Department of Medical Oncology, Harbin Medical University Cancer Hospital, 150 Haping Road, Harbin, Heilongjiang 150081, P.R. China E-mail: zhang_qingyuan163@163.com

\section{Abbreviations: GA-A, Ganoderic acid A}

Key words: Ganoderic acid A, triple-negative breast cancer, Janus kinase 2, signal transducer and activator of transcription 3, apoptosis may regulate associated targets to serve an anti-MDA-MB-231 role, including mitochondrial apoptosis and regulating the expression of cell-cycle-associated factors.

\section{Introduction}

Breast cancer is mortally harmful to females globally. Triple negative breast cancer (TNBC) exhibits poor prognosis, including poor distant free survival and overall survival rates (1). Given the lack of specific treatment for patients with TNBC, individuals are usually treated with conventional adjuvant chemotherapy (2), and do not experience sufficient curative effects (2). The lack of estrogen, progesterone and human endothelial growth factor receptor 2 receptors makes it difficult to optimize therapeutic management (2). Investigation into novel and specific agents is required to combat these problems.

The Janus kinase (JAK)2/signal transducer and activator of transcription (STAT)3 signaling pathway mediates the expression of various cytokines (3). Normally, this pathway is activated in response to certain cytokines and then regresses rapidly; however, in tumor cells, including breast cancer, lung cancer, hepatocellular carcinoma, pancreatic cancer, colorectal cancer, prostate cancer, ovarian carcinoma and gastric cancer, it is constitutively activated in a high level (4-11). Furthermore, the JAK2/STAT3 signaling pathway may modulate the expression of numerous genes and regulate various physiological functions. It targets a number of anti-apoptotic proteins, namely, B cell lymphoma-extra-large (Bcl-xL) and myeloid cell leukemia 1 (Mcl-1), in addition to cell cycle regulatory molecules and proteins associated with mitochondrial apoptosis [ $\mathrm{Bcl} 2$ associated $\mathrm{X}$ protein (Bax), $\mathrm{Bcl} 2$ antagonist/killer (Bak) and Caspase 3] (12). Mushroom Ganoderma lucidum, a traditional Chinese medicine, has been demonstrated to exhibit anti-cancer effects (13). However, the effective components have not been well studied. Ganoderic acid A (GA-A) is one of the major bioactive Ganoderma triterpenoids isolated from Ganoderma and has been revealed to have an effect on lymphoma growth (14), as well as in the promotion 
of cisplatin-induced cell death by inhibiting the JAK-STAT3 signaling pathway (15). In addition, it suppresses cancer cell proliferation and invasion and induces apoptosis in osteosarcoma (16). However, the effects and mechanisms of GA-A (Fig. 1) in human breast cancer require further investigation.

The present study aims to investigate the anticancer activity of GA-A in the human breast cancer cell line MDA-MB-231. The function of the JAK2-STAT3 signaling pathway was the focus of the present study and investigated the effects of GA-A in mitochondrial apoptosis and the cell cycle.

\section{Materials and methods}

Materials. GA-A (96\%) was purchased from Chengdu Must Bio-technology Co., Ltd., (Chengdu, China), dissolved in dimethylsulfoxide (DMSO) and maintained at $4^{\circ} \mathrm{C}$. AG490, MTT, and dichloro-dihydro-fluorescein diacetate (DCFH-DA) were obtained from Sigma-Aldrich (Merck KGaA, Darmstadt, Germany). The propidium iodide (PI) staining kit and the JC-1 fluorescent dye were purchased from Beyotime Institute of Biotechnology (Nanjing, China).

Cell culture and reagents. MDA-MB-231 breast cancer cells were obtained from the American Type Culture Collection (Manassas, VA, USA) and maintained with Leibovitz L-15 (L-15) medium ( $\mathrm{pH}=7.3$; Gibco; Thermo Fisher Scientific, Inc., Waltham, MA, USA) supplemented with $100 \mathrm{mg} / \mathrm{ml}$ streptomycin, $100 \mathrm{IU} / \mathrm{ml}$ penicillin and $10 \%$ fetal bovine serum (Beijing Solarbio Science \& Technology Co., Ltd., Beijing, China). Cells were maintained at $37^{\circ} \mathrm{C}$ and $5 \% \mathrm{CO}_{2}$, and the medium was refreshed every 3 days. The GA-A was diluted in L-15 immediately prior to experiments. The control group was treated with L-15 $(0.01 \%)$ alone. Cells were first treated with GA-A $(0.1,0.2$ and $0.4 \mathrm{mmol} / \mathrm{l})$, then with $0.4 \mathrm{mmol} / \mathrm{l} \mathrm{GA}-\mathrm{A}$ and $20 \mu \mathrm{M}$ AG490 at $37^{\circ} \mathrm{C}$ for $24 \mathrm{~h}$. Cells were harvested at 24 or $48 \mathrm{~h}$.

Cell viability. Cell viability was investigated using an MTT assay. Cells $\left(5 \times 10^{3}\right)$ were treated with GA-A $(0.01,0.02,0.05$, $0.1,0.2,0.4,0.6$ and $0.8 \mathrm{mmol} / \mathrm{l})$ for exactly $24 \mathrm{~h}$ then $20 \mathrm{ml}$ MTT at $5 \mathrm{mg} / \mathrm{ml}$ for $4 \mathrm{~h}$ at $37^{\circ} \mathrm{C}$. The supernatant was then removed and $150 \mathrm{ml}$ DMSO was added. After $15 \mathrm{~min}$, the $490 \mathrm{~nm}$ optical density value was measured. The results were presented as the ratio between the control group and research group.

Transwell invasion assay. A Transwell chamber (8 $\mu \mathrm{m}$ pore polycarbonate; Corning Incorporated, Corning, NY, USA) with Matrigel (BD Biosciences, Franklin Lakes, NJ, USA) was used in this experiment. Cells were seeded $\left(1 \times 10^{6}\right)$ into the upper chambers of 24-transwell chamber wells and treated with GA-A $(0.1,0.2$ and $0.4 \mathrm{mmol} / \mathrm{l})$ at $37^{\circ} \mathrm{C}$ for $24 \mathrm{~h}$. For the invasion assay, the cells were plated in the upper chamber in the serum-free L-15 medium. The medium containing $20 \%$ of FBS in the lower chamber served as a chemoattractant. Following incubation for $24 \mathrm{~h}$, cells in the upper chambers were removed with a cotton swab. Subsequently, cells were fixed with $100 \%$ methanol and then stained with $1 \%$ crystal violet in $2 \%$ ethanol for $10 \mathrm{~min}$ at room temperature. Under a Nikon light microscope (x100),

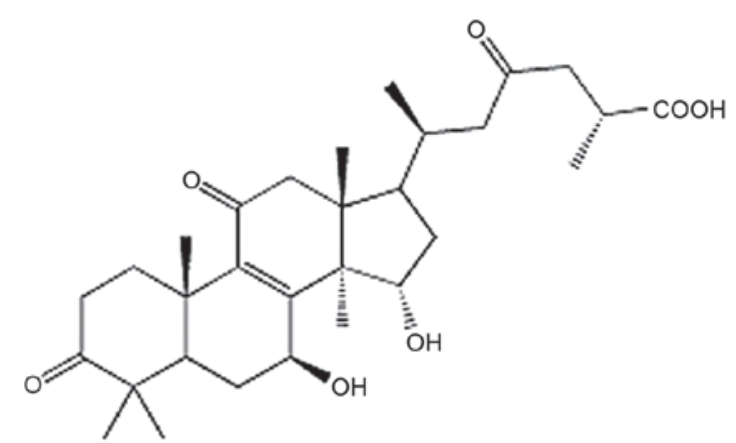

Figure 1. Structure of Ganoderic acid A.

migrated cells were counted and images were captured at five different fields of the chamber.

Cell apoptosis detection. Cells were seeded into 6-well plates $\left(5 \times 10^{5}\right.$ cell/well) and incubated for $24 \mathrm{~h}$ prior to treatment. GA-A (0, 0.1, 0.2 and $0.4 \mathrm{mmol} / 1$, respectively) or DMSO were added to the plate and incubated at $37^{\circ} \mathrm{C}$ for 1 day. Subsequently, adherent cells and non-adherent cells were digested in trypsin at $37^{\circ} \mathrm{C}$ for $2 \mathrm{~min}$. The cell suspension was incubated with $10 \mathrm{ml} \mathrm{PI}$ and $5 \mathrm{ml}$ annexin V-fluorescein isothiocyanate (from the kit aforementioned) for $10 \mathrm{~min}$ in the dark at $37^{\circ} \mathrm{C}$ and then analyzed using a flow cytometer (BD Canto II) and Diva Software v7.0 (BD Biosciences). The apoptotic index in Fig. 3 was calculated as: Apoptotic cells/total cells x100\%.

Analysis of reactive oxygen species (ROS). Intracellular ROS production was investigated using DCFH-DA. Cells were seeded at a density of $1 \times 10^{6}$ cells/well and cultured for $24 \mathrm{~h}$. Cells were then harvested in trypsin at $37^{\circ} \mathrm{C}$ for $2 \mathrm{~min}$, washed with PBS for $5 \mathrm{~min}$ and re-suspended in $500 \mu \mathrm{l}$ PBS containing $20 \mu \mathrm{M}$ DCFH-DA then incubated at $37^{\circ} \mathrm{C}$ for $20 \mathrm{~min}$ in the dark. The cells were harvested and analyzed by flow cytometry (BD Canto II) and Diva Software v7.0.

Western blot analysis. The treated cells $\left(1 \times 10^{7}\right.$ cells $/ 6 \mathrm{ml}$ L-15 with $10 \%$ FBS in a $90-\mathrm{mm}$ dish) were collected and washed twice using cold PBS for $5 \mathrm{~min}$. Cells were lysed in $200 \mu 1$ lysis radioimmunoprecipitation assay buffer (Beyotime Institute of Biotechnology). The lysate was incubated on ice for $30 \mathrm{~min}$, vortexed and centrifuged at $14,000 \mathrm{x} \mathrm{g}$ for $15 \mathrm{~min}$ at $4^{\circ} \mathrm{C}$. The supernatant was collected and protein concentration was determined using a Bradford Assay. Following the addition of SDS-PAGE sample loading buffer (Beyotime Institute of Biotechnology), the protein samples $(30 \mu \mathrm{g})$ underwent electrophoresis using a 10\% SDS-PAGE and were then transferred to a polyvinylidene fluoride membrane (EMD Millipore, Billerica, MA, USA). After blocking for $4 \mathrm{~h}$ at room temperature in a solution of $5 \%$ non-fat dry milk in Tris-buffered saline containing $0.1 \%$ Tween-20, the membranes were incubated overnight at $4^{\circ} \mathrm{C}$ with the primary antibodies against phosphorylated (p)-JAK2 (catalog no. 3771), JAK2 (catalog no. 3230), p-STAT3 (catalog no. 9145), STAT3 (catalog no. 9139), Bcl-xL (catalog no. sc-8392), Bak (catalog no. sc-517390), Mcl-1 (catalog no. sc-12756), Bax (catalog no. sc-7480), Cytochrome c (catalog no. sc-13156) and 
A

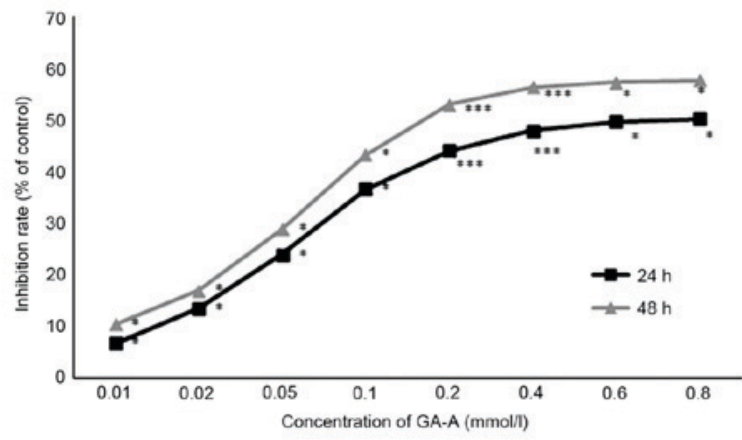

B

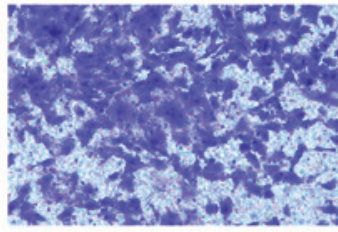
Control

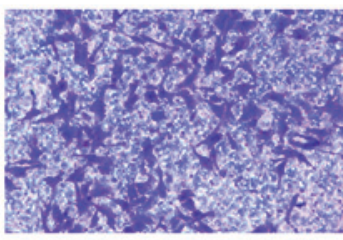

$\mathrm{GA}-\mathrm{A} 0.2 \mathrm{mmol} / \mathrm{l}$

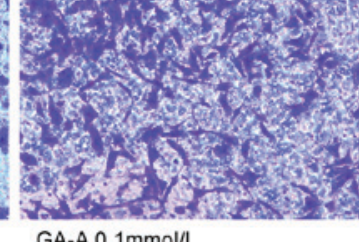
GA-A $0.1 \mathrm{mmol} / \mathrm{l}$

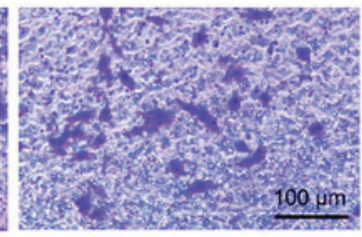

GA-A $0.4 \mathrm{mmol} / \mathrm{I}$

Figure 2. GA-A inhibited the viability and invasive capacity of MDA-MB-231 cells. (A) GA-A inhibited MDA-MB-231 cell viability in a dose and time dependent manner. ${ }^{*} \mathrm{P}<0.05$ vs. control group, ${ }^{* * * *} \mathrm{P}<0.001$ vs. control. (B) GA-A inhibits MDA-MB-231 cell invasive capacity. GA-A, Ganoderic acid A.

$\beta$-actin (catalog no. sc-47778) at a concentration of $1: 1,000$ in Tris-buffered saline with $0.1 \%$ Tween-20 containing 5\% non-fat dry milk. JAK2, p-JAK2, p-STAT3, STAT3 primary antibodies were obtained from Cell Signaling Technology, Inc. (Danvers, MA, USA). Bcl-xL, Bak, Mcl-1, Bax, Cytochrome $c$ and $\beta$-actin primary antibodies were purchased from Santa Cruz Biotechnology, Inc. (Dallas, TX, USA). Following washing four times for $5 \mathrm{~min}$, the membranes were incubated with a horseradish peroxidase-conjugated secondary anti-rabbit IgG antibody (1:5,000 dilution; catalog no. 7074; Cell Signaling Technology, Inc.) at room temperature for $1 \mathrm{~h}$ and were then washed six times for $10 \mathrm{~min}$. Signals were detected with an enhanced chemiluminescence detection kit (Applygen Technologies, Inc., Beijing, China).

Statistical analysis. Statistical analysis was performed using SPSS 14.0 software (SPSS Inc., Chicago, IL, USA). Values presented as the mean \pm standard deviation and were analyzed using one-way analysis of variance, followed by Tukey's post hoc test. $\mathrm{P}<0.05$ was considered to indicate a statistically significant difference.

\section{Results}

GA-A inhibits MDA-MB-231 cell viability. MDA-MB-231 cells were stimulated by GA-A $(0.1-0.8 \mathrm{mmol} / \mathrm{l})$ to determine its effect on cell viability. GA-A significantly decreased cell viability compared with the control group, and the effects were not only dose dependent but also time dependent $(\mathrm{P}<0.05$;
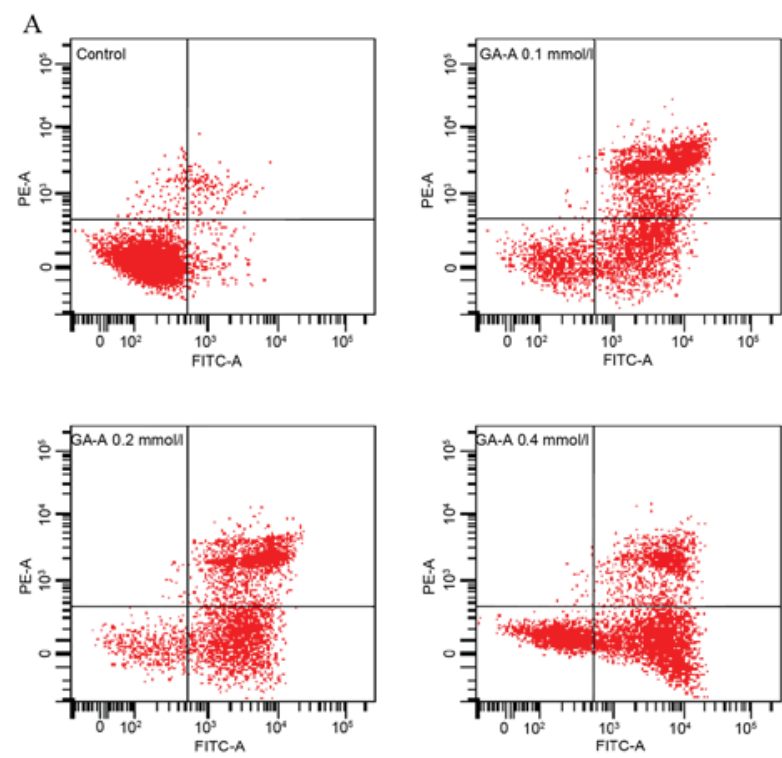

B

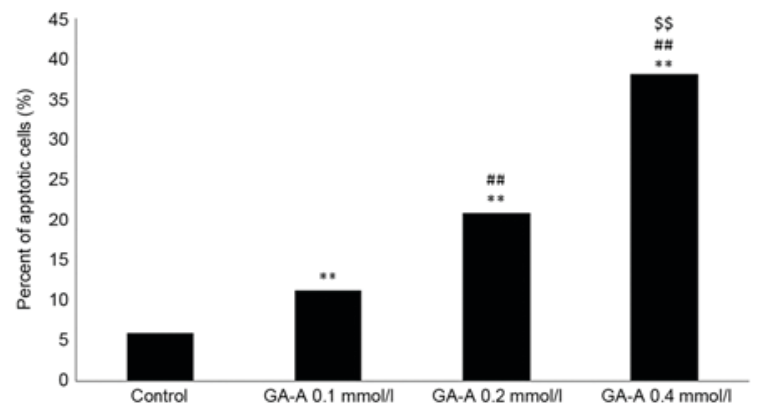

Figure 3. GA-A induced the apoptosis of MDA-MB231 cells. (A) GA-A induced MDA-MB-231 apoptosis as measured by flow cytometry and (B) quantified. ${ }^{* *} \mathrm{P}<0.01$ vs. control, ${ }^{\# \#} \mathrm{P}<0.01$ vs. GA-A $0.1 \mathrm{mmol} / 1$ group, ș $\mathrm{P}<0.01$ vs. GA-A $0.2 \mathrm{mmol} / 1$ group. GA-A, Ganoderic acid A; PE, phycoerythrin; FITC, fluorescein isothiocyanate.

Fig. 2A). The half-maximal inhibitory concentrations of GA-A at 24 and $48 \mathrm{~h}$ were 0.707 and $0.163 \mathrm{mmol} / \mathrm{l}$, respectively.

GA-A inhibits MDA-MB-231 cell invasive capacity. Based on the results of the Transwell invasion assay, GA-A demonstrated an inhibitory effect on the invasion of MDA-MB-231 cells. Fig. 2B reveals that following incubation for $24 \mathrm{~h}, \mathrm{GA}-\mathrm{A}$ $(0.1,0.2$ and $0.4 \mathrm{mmol} / \mathrm{l})$ markedly decreased the number of invasive cells. As GA-A concentration increased, the MDA-MB-231 cells became less invasive. These results were consistent with the Transwell invasion assay, which indicated that GA-A suppressed the invasion of MDA-MB-231 cells.

GA-A induces breast cancer cell apoptosis. MDA-MB-231 cells were untreated or treated with GA-A $(0.1,0.2$ and $0.4 \mathrm{mmol} / \mathrm{l}$ ) for $24 \mathrm{~h}$. Following treatment with $0.1,0.2$ and $0.4 \mathrm{mmol} / \mathrm{l}$ of GA-A for $24 \mathrm{~h}$, the apoptotic index increased by $11.34 \pm 3.41,20.89 \pm 3.32$ and $38.13 \pm 3.91 \%$, respectively $(\mathrm{P}<0.01$, vs. control). The effect of GA-A on apoptosis was dose-dependent. These results indicate that GA-A induces apoptosis of MDA-MB-231 cells (Fig. 3B).

GA-A leads to ROS accumulation. As presented in Fig. 4, ROS level markedly increased following GA-A treatment. ROS 

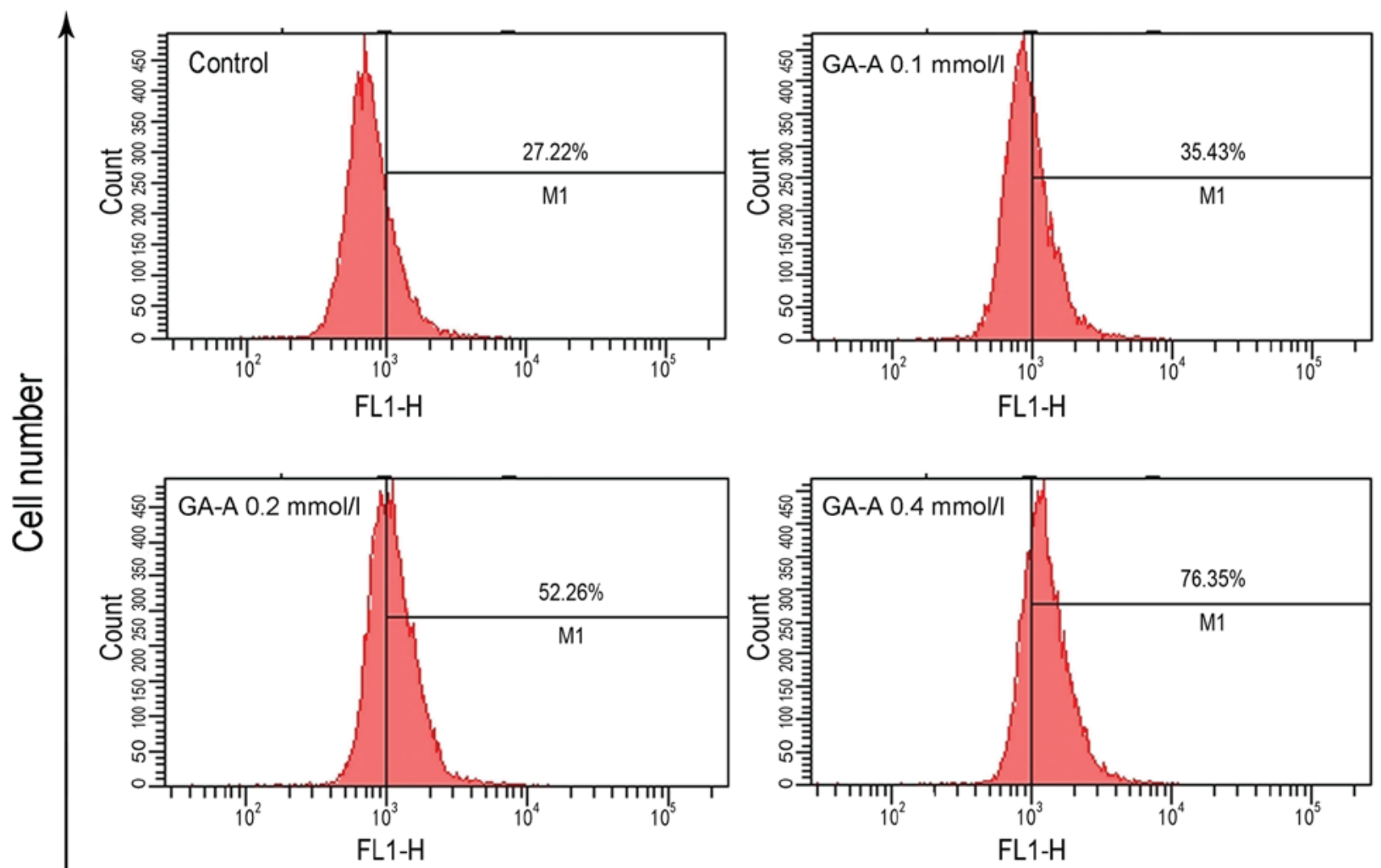

Figure 4. GA-A upregulated reactive oxygen species levels in MDA-MB-231 cells. MDA-MB-231 cells were (A) untreated or treated with GA-A (B) 0.1 mmol/1, (C) $0.2 \mathrm{mmol} / 1$ and (D) $00.4 \mathrm{mmol} / 1$ for $24 \mathrm{~h}$. GA-A, Ganoderic acid A.

production following $0.4 \mathrm{mmol} / \mathrm{l} \mathrm{GA}-\mathrm{A}$ increased markedly from $27.22 \%$ in the control group to $76.35 \%$.

Effects of GA-A on cell cycle-regulated protein expression. Western blot analysis was applied to determine cyclin D1, p21 and p27 protein expression to further investigate the characteristics of the observed G0-G1 phase control. It was revealed that cyclin D1 expression significantly decreased compared with the control, whereas p21 and p27 expression significantly increased $(\mathrm{P}<0.05$; Fig. 5), which indicates that distinctions exist between cell-cycle-associated protein, at least partially, leading to G0-G1 phase arrest by GA-A.

Effects of GA-A on the JAK2/STAT3 signaling pathway and mitochondrial apoptosis. Western blot analysis was adopted to assess the phosphorylated forms of JAK2 and STAT3 in breast cancer cells stimulated by GA-A, from which the phosphorylation of these factors was revealed to significantly decrease following GA-A treatment (with the exception of p-JAK2 at $0.1 \mathrm{mmol} / 1 \mathrm{GA}-\mathrm{A} ; \mathrm{P}<0.05)$. In addition, the expression levels of $\mathrm{Mcl}-1$ and $\mathrm{Bcl}-\mathrm{xL}$ were significantly downregulated by GA-A dose-dependently compared with the control, in accordance with decreased phosphorylated JAK2 and STAT3 (P<0.05; Fig. 6). Additionally, GA-A treatment significantly enhanced the levels of mitochondrial apoptotic pathway-associated proteins (Bak, Bax, and cytosolic cytochrome $\mathrm{C}$ ) compared with the control and in a dose dependent manner $(\mathrm{P}<0.05)$, suggesting the mitochondrial apoptosis occurred.

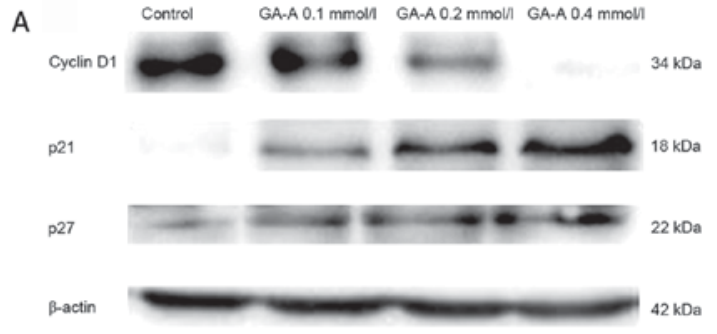

B

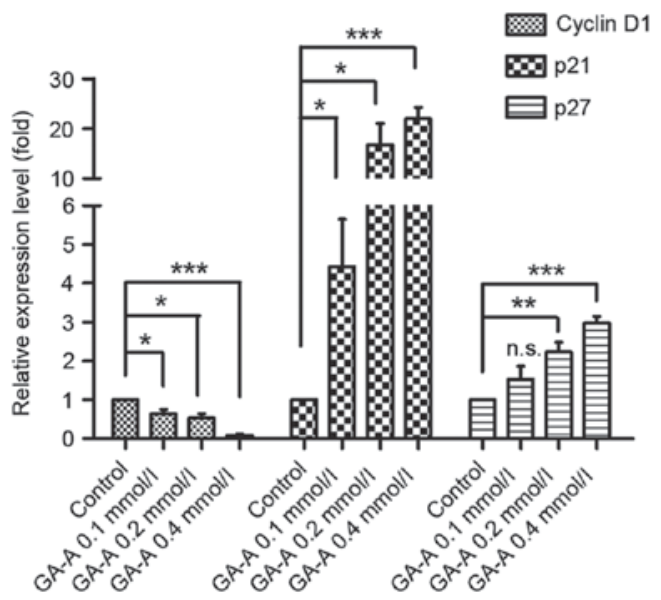

Figure 5. GA-A affected the expression of cell cycle association proteins cyclin D1, p21 and p27 in MDA-MB-231 cells. (A) Western blot analysis and (B) quantified relative expression. ${ }^{* * *} \mathrm{P}<0.001,{ }^{* *} \mathrm{P}<0.01,{ }^{*} \mathrm{P}<0.05$ vs GA-A-untreated control. GA-A, Ganoderic acid A; n.s., not significant. 


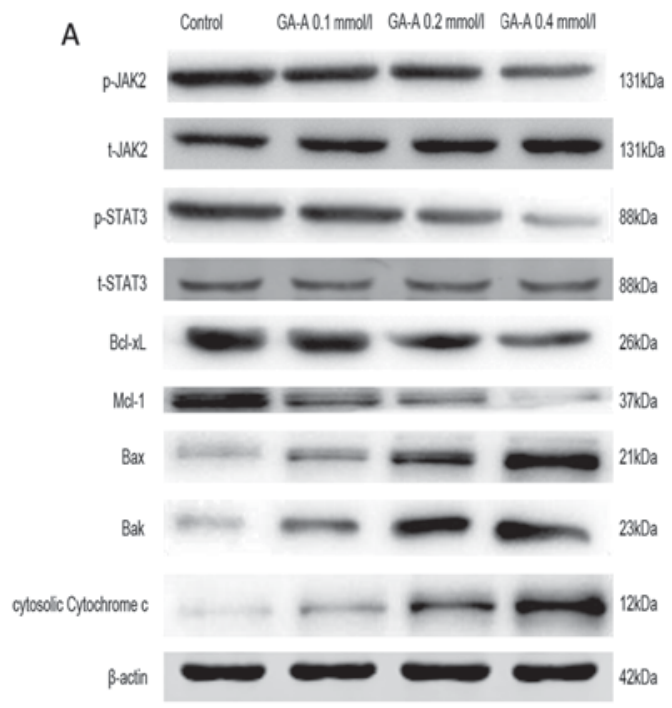

$\mathrm{F}$

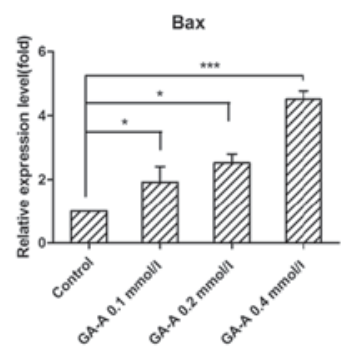

B

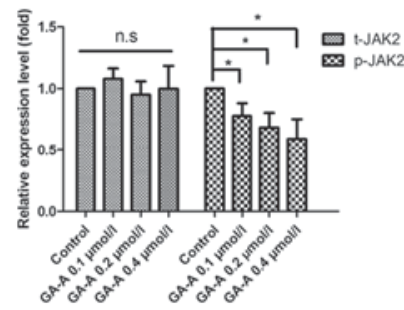

D

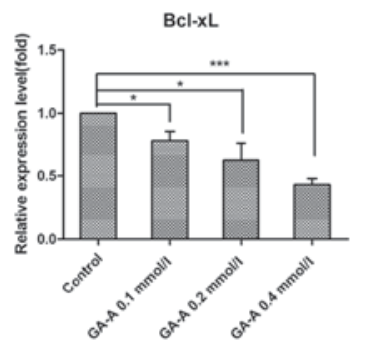

G

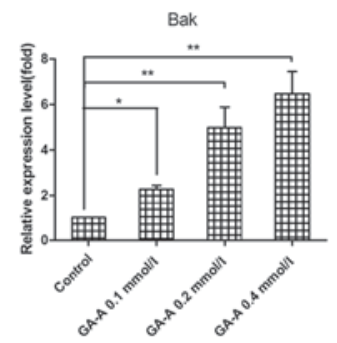

C

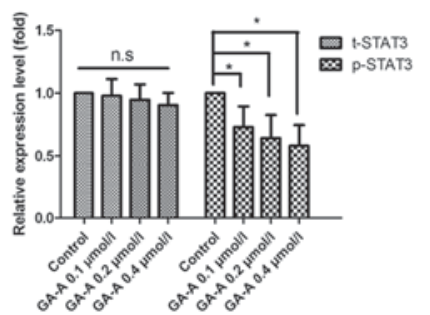

E

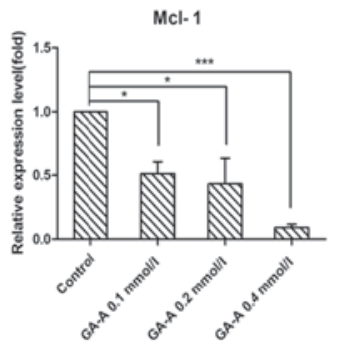

$\mathrm{H}$

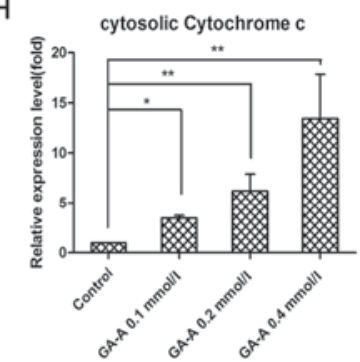

Figure 6. GA-A affected JAK2/STAT3 signaling pathway and mitochondrial apoptotic pathway associated proteins in MDA-MB-231 cells. (A) The bands of western blot analysis. $\beta$-actin was used as an internal control. (B) Statistical charts of the relative expression levels of t-JAK2 and p-JAK2. (C) Statistical charts of the relative expression levels of t-STAT3 and p-STAT3. (D) Statistical charts of the relative expression levels of Bcl-xL. (E) Statistical charts of the relative expression levels of Mcl-1. (F) Statistical charts of the relative expression levels of Bax. (G) Statistical charts of the relative expression levels of Bak. (H) Statistical charts of the relative expression levels of cytosolic Cytochrome c. ${ }^{* * *} \mathrm{P}<0.001,{ }^{* *} \mathrm{P}<0.01,{ }^{*} \mathrm{P}<0.05$ vs. GA-A-untreated control. GA-A, Ganoderic acid A; STAT, signal transducer and activator of transcription; JAK, Janus kinase; Bcl-xL, B cell lymphoma-extra-large; Mcl-1, myeloid cell leukemia 1; Bax, Bcl2 associated X protein; Bak, Bcl2 antagonist/killer; n.s., not significant; p-, phosphorylated; t-, total.

Effects of GA-A/AG490 combined treatment on the JAK2/STAT3 signaling pathway. The combined treatment of GA-A and AG490 further decreased JAK2/STAT3 expression levels compared with the control ( $\mathrm{P}<0.01$; Fig. 7). This result suggests that the anti-breast cancer effects of GA-A may involve other mechanisms, including JAK2/STAT3. Thus, the result supports the hypothesis that the antitumor effects of GA-A are associated with certain molecules, including Bcl-xL, Bak, Mcl-1 and Bax, and the JAK2/STAT3 signaling pathways.

\section{Discussion}

In the present study, it was demonstrated that GA-A decreases cell viability, induces apoptosis and suppresses the invasion of human MDA-MB-231 cells in vitro. Previously, the effects of GA-A have been demonstrated in lymphoma, hepatocellular carcinoma and osteosarcoma cells (12-14), in which cellular proliferation, colony formation and invasive behaviors were revealed to be suppressed by GA-A in osteosarcoma, which is similar to the results of the present study in breast cancer.

JAK/STAT transduces a series of signals that are critical for physiological development or homeostasis. JAK1, JAK2, JAK3 and thymidine kinase 2 constitute the JAK family, which is involved in proliferation, migration and apoptosis (17). Constitutively activated JAKs phosphorylate a number of substrates, including STAT3; and these substrates are commonly associated with oncogenic signaling pathways $(18,19)$. STAT3 activation in regulating tumor cell metastasis, proliferation, apoptosis, invasion, migration and angiogenesis has been demonstrated in previous studies, revealing its critical function (20-22). Distinct human cancer cell lines and tumor tissues were previously studies to detect the persistent activation of STAT3 through the use of various experiments (23-29). Based on a number of previous studies, the proliferation and survival of various types of cancer were suppressed by the inhibition of STAT3 with a dominant negative form of STAT3 or other inhibitors $(21,30)$. The results of the present study revealed that the anti-MDA-MB-231 function of GA-A worked through the JAK2/STAT3 signaling pathway, and indicated that the activities of JAK2 and STAT3 were directly prohibited by GA-A treatment, which also inhibited the expression of Bcl-xL and Mcl-1. Additionally, cell viability was also further decreased by GA-A when combined with AG490. In addition to JAK2/STAT3, it was demonstrated that other mechanisms were involved in the anti-MDA-MB-231 effect of GA-A. These results suggest that a considerable number of 


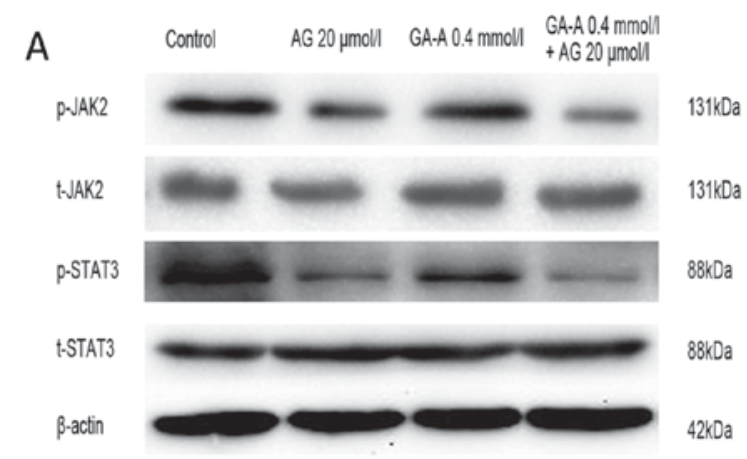

B

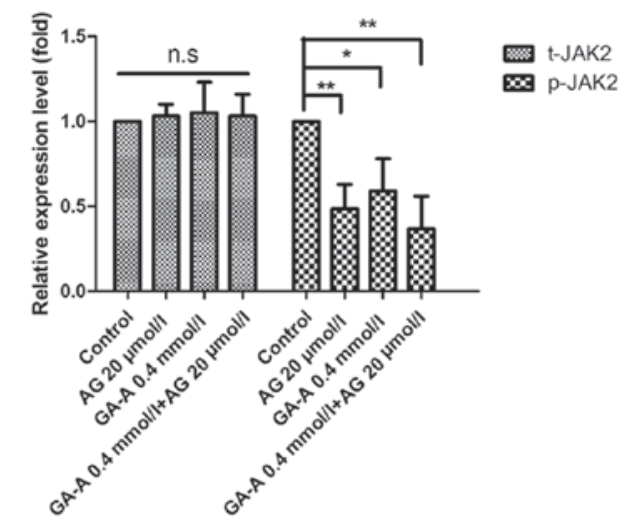

C

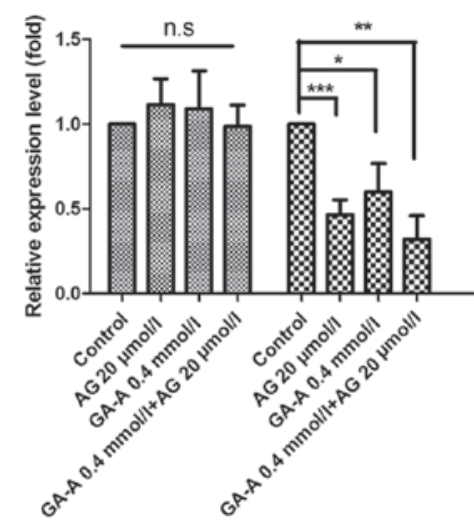

$\begin{array}{ll}\text { t-STAT3 } \\ \mathbf{x} & \text { p-STAT3 }\end{array}$

Figure 7. Effects of GA-A combined with AG490 on JAK2/STAT3 signaling. (A) The bands of western blot analysis. $\beta$-actin was used as an internal control. Relative expression levels of (B) p-JAK2 and (C) p-STAT3. ${ }^{* * *} \mathrm{P}<0.001,{ }^{* *} \mathrm{P}<0.01,{ }^{*} \mathrm{P}<0.05$ vs. GA-A-untreated control. GA-A, Ganoderic acid A; STAT, signal transducer and activator of transcription; JAK, Janus kinase; n.s., not significant; p-, phosphorylated; t-, total.

molecules and pathways are associated with the anticancer properties of GA-A.

There are two apoptotic signaling pathways in mitochondria: One is the intrinsic, and the other is the extrinsic. The former is more commonly observed in chemotherapy (31), including the important members cytochrome c, caspase3, Bak and Bax (32). Suppression of the JAK2/STAT3 signaling pathway induces apoptosis through the mitochondrial apoptotic pathway $(33,34)$. Additionally, one of the sources for ROS is from the mitochondria during the process of apoptosis (35). The results of the present study demonstrate that GA-A significantly increased expression of proteins associated with ROS generation and mitochondrial apoptosis. This supported previous studies that suggested that for human cancer cells, mitochondrial apoptosis is associated with inhibiting JAK2/STAT3 $(33,34)$.

As a cell cycle regulator, cyclin D1 regulates G1 cells entering the S-phase and serves a function as a cofactor for a number of transcription factors (36). Cyclin D1 overexpression may contribute to cancer incidence (37). p21 and p27, as CDK inhibitors (CDKIs), attenuate cancer cell proliferation with their upregulation (38). It has previous been demonstrated that JAK2/STAT3 phosphorylation is suppressed by WP1193 inhibiting glioma stem-like cell proliferation and sphere formation; the reason for this effect partially lies in decreased cyclin D1 and increased p21 expression (39). Research on colon cancer cells also suggests that STAT3 controls the balance between CDK/cyclin and CDKIs (34). The present study demonstrated that GA-A treatment may result in delays in the cell cycle in G0-G1 phase. Furthermore, a decrease was observed in cyclin D1 expression but conversely an increase in p21 and p27 expression in MDA-MB-231 cells following GA-A treatment, compared with the control. Collectively, the results of the present study provide supporting evidence for JAK2/STAT3 in the counterpoise.

According to the result of the present study, GA-A treatment inhibits MDA-MB-231 cell viability by inhibiting the JAK2/STAT3 signaling pathway, and GA-A regulates various targets that jointly generate the anti-MDA-MB-231 effects. These effects include affecting the pathways involved in the mitochondrial apoptosis and cell cycle control.

\section{Acknowledgements}

The present study was completed in the Oncology Key Lab of the Heilongjiang Province Institution of Higher Education.

\section{Funding}

No funding was received.

\section{Availability of data and materials}

The datasets used and/or analyzed during the present study are available from the corresponding author on reasonable request.

\section{Authors' contributions}

YY performed the experiments, drafted the manuscript and analyzed the data. HZ assisted with the data analysis. JCW participated in the cell culture, reagents and viability experiments. LQ participated in the cell apoptosis detection and analysis of ROS. HL and LG participated in the western blot analysis. XY, WL and JW assisted with the experiments. ZW and XL participated in the study design and coordination and helped to revised the manuscript. QZ was responsible for the study design and final approval of the manuscript. All authors read and approved the final version of the manuscript.

\section{Ethics approval and consent to participate}

Not applicable. 


\section{Patient consent for publication}

Not applicable.

\section{Competing interests}

The authors declare that they have no competing interests.

\section{References}

1. Foulkes WD, Smith IE and Reis-Filho JS: Triple-negative breast cancer. N Engl J Med 363: 1938-1948, 2010.

2. Sun S, Zhao Y and Xu K: Post-adjuvant chemotherapy for triple-negative breast cancer. Med Hypotheses 90: 74-75, 2016.

3. Wang X, Crowe PJ, Goldstein D and Yang JL: STAT3 inhibition, a novel approach to enhancing targeted therapy in human cancers (review). Int J Oncol 41: 1181-1191, 2012.

4. Kim MS, Lee WS, Jeong J, Kim SJ and Jin W: Induction of metastatic potential by TrkB via activation of IL6/JAK2/STAT3 and PI3K/AKT signaling in the breast cancer. Oncotarget 6 : 40158-40171, 2015 .

5. Wu L, Guo L, Liang Y, Liu X, Jiang L and Wang L: Curcumin suppresses stem-like traits of lung cancer cells via inhibiting the JAK2/STAT3 signaling pathway. Oncol Rep 34: 3311-3317, 2015.

6. Zhao H, Guo Y, Li S, Han R, Ying J, Zhu H, Wang Y, Yin L, Han Y, Sun L, et al: A novel anti-cancer agent Icaritin suppresses hepatocellular carcinoma initiation and malignant growth through the IL-6/Jak2/Stat3 pathway. Oncotarget 6: 31927-31943, 2015.

7. Liu X, Wang J, Wang H, Yin G, Liu Y, Lei X and Xiang M: REG3A accelerates pancreatic cancer cell growth under IL-6-associated inflammatory condition: Involvement of a REG3A-JAK2/STAT3 positive feedback loop. Cancer Lett 362: 45-60, 2015.

8. Wang SW, Hu J, Guo QH, Zhao Y, Cheng JJ, Zhang DS, Fei Q, Li J and Sun YM: AZD1480, a JAK inhibitor, inhibits cell growth and survival of colorectal cancer via modulating the JAK2/STAT3 signaling pathway. Oncol Rep 32: 1991-1998, 2014.

9. Jorvig JE and Chakraborty A: Zerumbone inhibits growth of hormone refractory prostate cancer cells by inhibiting JAK2/STAT3 pathway and increases paclitaxel sensitivity. Anticancer Drugs 26: 160-166, 2015.

10. Gritsina G, Xiao F, O'Brien SW, Gabbasov R, Maglaty MA, Xu RH, Thapa RJ, Zhou Y, Nicolas E, Litwin S, et al: Targeted blockade of JAK/STAT3 signaling inhibits ovarian carcinoma Growth. Mol Cancer Ther 14: 1035-1047, 2015.

11. Judd LM, Menheniott TR, Ling H, Jackson CB, Howlett M, Kalantzis A, Priebe W and Giraud AS: Inhibition of the JAK2/STAT3 pathway reduce gastric cancer growth in vitro and in vivo. PLoS One 9: e95993, 2014.

12. Liu Y, Wang L, Wu Y, Lv C, Li X, Cao X, Yang M, Feng D and Luo Z: Pterostilbene exerts antitumor activity against human osteosarcoma cells by inhibiting the JAK2/STAT3 signaling pathway. Toxicology 304: 120-131, 2013.

13. Ruan W, Wei Y and Popovich DG: Distinct responses of cytotoxic Ganoderma lucidum trierpenoids in human carcinoma cells. Phytother Res 29: 1744-1752, 2015.

14. Radwan FF, Hossain A, God JM, Leaphart N, Elvington M, Nagarkatti $M$, Tomlinson $S$ and Haque A: Reduction of myeloid-derived suppressor cells and lymphoma growth by a natural triterpenoid. J Cell Biochem 116: 102-114, 2015.

15. Yao X, Li G, Xu H and Lü C: Inhibition of the JAK-STAT3 signaling pathway by ganoderic acid A enhances chemosensitivity of HepG2 cells to cisplatin. Planta Med 78: 1740-1748, 2012

16. Shao J, Li Z, Jiao G, Sun G and Zhou Z: Ganoderic acid A suppresses proliferation and invasion and induces apoptosis in human osteosarcoma cells. Nan Fang Yi Ke Da Xue Xue Bao 35 619-624, 2015 (In Chinese).

17. Quintás-Cardama A and Verstovsek S: Molecular pathways: JAK/STAT pathway: Mutations, inhibitors, and resistance. Clin Cancer Res 19: 1933-1940, 2013.

18. Buchert M, Burns CJ and Ernst M: Targeting JAK kinase in solid tumors: Emerging opportunities and challenges. Oncogene 35: 939-951, 2016.

19. Khanna P, Chua PJ, Bay BH and Baeg GH: The JAK/STAT signaling cascade in gastric carcinoma (Review). Int J Oncol 47: $1617-1626,2015$
20. O'Shea JJ, Holland SM and Staudt LM: JAKs and STATs in immunity, immunodeficiency, and cancer. N Engl J Med 368: 161-170, 2013.

21. Bowman T, Garcia R, Turkson J and Jove R: STATs in oncogenesis. Oncogene 19: 2474-2488, 2000.

22. Yu H,Pardoll D and Jove R: STATs in cancer inflammation and immunity: A leading role for STAT3. Nat Rev Cancer 9: 798-809, 2009.

23. Walker SR, Xiang M and Frank DA: STAT3 activity and function in cancer: Modulation by STAT5 and miR-146b. Cancers (Basel) 6: 958-968, 2014.

24. He G and Karin M: NF- $\kappa$ B and STAT3-key players in liver inflammation and cancer. Cell Res 21: 159-168, 2011.

25. Frank DA: STAT3 as a central mediator of neoplastic cellular transformation. Cancer Lett 251: 199-210, 2007.

26. Schroeder A, Herrmann A, Cherryholmes G, Kowolik C, Buettner R, Pal S, Yu H, Müller-Newen G and Jove R: Loss of androgen receptor expression promotes a stem-like cell phenotype in prostate cancer through STAT3 signaling. Cancer Res 74: 1227-1237, 2014.

27. Lin L, Liu A, Peng Z, Lin HJ, Li PK, Li C and Lin J: STAT3 is necessary for proliferation and survival in colon cancer-initiating cells. Cancer Res 71: 7226-7237, 2011.

28. Kim DY, Cha ST, Ahn DH, Kang HY, Kwon CI, Ko KH, Hwang SG, Park PW, Rim KS and Hong SP: STAT3 expression in gastric cancer indicates a poor prognosis. J Gastroenterol Hepatol 24: 646-651, 2009.

29. Wei D, Le X, Zheng L, Wang L, Frey JA, Gao AC, Peng Z, Huang S, Xiong HQ, Abbruzzese JL and Xie K: Stat3 activation regulates the expression of vascular endothelial growth factor and human pancreatic cancer angiogenesis and metastasis. Oncogene 22: 319-329, 2003

30. Kamran MZ, Patil P and Gude RP: Role of STAT3 in cancer metastasis and translational advance. Biomed Res Int 2013: 421821, 2013.

31. Li Y, Yang F, Zheng W, Hu M, Wang J, Ma S, Deng Y, Luo Y, Ye T and Yin W: Punica granatum (pomegranate) leaves extract induces apoptosis through mitochondrial intrinsic pathway and inhibits migration and invasion in non-small cell lung cancer in vitro. Biomed Pharmacother 80: 227-235, 2016.

32. Li X, Zhang Q, Cai L, Wang Y, Wang Q, Huang X, Fu S, Bai J, Liu J, Zhang $\mathrm{G}$ and Qi J: Inhibitor of growth 4 induces apoptosis in human lung adenocarcinoma cell line A549 via Bcl-2 family proteins and mitochondria apoptosis pathway. J Cancer Res Clin Oncol 135: 829-835, 2009.

33. Su JC, Lin KL, Chien CM, Chuang PW, Chang LS and Lin SR: Concomitant inactivation of the epidermal growth factor receptor, phosphatidylinositol 3-kinase/Akt and Janus tyrosine kinase 2 /signal transducer and activator of transcription 3 signalling pathways in cardiotoxin III-treated A549 cells. Clin Exp Pharmacol Physiol 37: 833-840, 2010.

34. Du W, Hong J, Wang YC, Zhang YJ, Wang P, Su WY, Lin YW, Lu R, Zou WP, Xiong H and Fang JY: Inhibition of JAK2/STAT3 signalling induces colorectal cancer cell apoptosis via mitochondrial pathway. J Cell Mol Med 16: 1878-1888, 2012.

35. Bhardwaj M, Kim NH, Paul S, Jakhar R, Han J and Kang SC: 5-Hydroxy-7-methoxyflavone triggers mitochondrial-associated cell death via reactive oxygen species signaling in human colon carcinoma cells. PLoS One 11: e0154525, 2016.

36. Zhang F, Wang Z, Yuan J, Wei X, Tian R and Niu R: RNAi-mediated silencing of Anxa2 inhibits breast cancer cell proliferation by downregulating cyclin D1 in STAT3-dependent pathway. Breast Cancer Res Treat 153: 263-275, 2015.

37. Cai Q, Lin J, Wei L, Zhang L, Wang L, Zhan Y, Zeng J, Xu W, Shen A, Hong Z and Peng J: Hedyotis diffusa Willd inhibits colorectal cancer growth in vivo via inhibition of STAT3 signaling pathway. Int J Mol Sci 13: 6117-6128, 2012.

38. Zhou Y,Zeng Z,Zhang W, Xiong W, Wu M, Tan Y, YiW, Xiao L,LiX, Huang C, et al: Lactotransferrin: A candidate tumor suppressor-deficient expression in human nasopharyngeal carcinoma and inhibition of NPC cell proliferation by modulating the mitogen-activated protein kinase pathway. Int J Cancer 123: 2065-2072, 2008.

39. Sai K, Wang S, Balasubramaniyan V,Conrad C,Lang FF, Aldape K Szymanski S, Fokt I, Dasgupta A, Madden T, et al: Induction of cell-cycle arrest and apoptosis in glioblastoma stem-like cells by WP1193, a novel small molecule inhibitor of the JAK2/STAT3 pathway. J Neurooncol 107: 487-501, 2012.

This work is licensed under a Creative Commons Attribution-NonCommercial-NoDerivatives 4.0 International (CC BY-NC-ND 4.0) License. 